\title{
Interventional Bronchus Occlusion Using Amplatzer Devices - A Promising Treatment Option for Children with Persistent Air Leak
}

\author{
Interventionelle Bronchusokklusion mit Amplatzer Okkludern: \\ Eine vielversprechende Therapieoption für Kinder mit \\ persistierender Luftleckage
}

\section{Authors}

Katharina Schütz ${ }^{1,2^{*}}$, Christoph M. Happel ${ }^{3}$, Oliver Keil ${ }^{4}$, Jens Dingemann ${ }^{5}$, Julia Carlens ${ }^{1}$, Martin Wetzke', Carsten Müller ${ }^{1}$, Harald Köditz ${ }^{6}$, Matthias Griese ${ }^{7}$, Karl Reiter ${ }^{7}$, Andrea Schweiger-Kabesch ${ }^{8}$, Alexander Backendorf ${ }^{9}$, Anna Zychlinsky Scharff ${ }^{10}$, Harald Bertram ${ }^{6}$, Nicolaus Schwerk ${ }^{1,11}$

\section{Affiliations}

1 Department of Paediatric Pulmonology, Allergology and Neonatology, Hannover Medical School Centre for Paediatrics and Adolescent Medicine, Hannover, Deutschland

2 Excellence Cluster RESIST - Resolving Infection Susceptibility, Hannover Medical School, Hannover, Deutschland

3 Pediatric Cardiology and Pediatric Intensive Care, Hanover Medical Specialists, Hanover, Deutschland

4 Department of Anesthesiology and Intensive Care Medicine, Hannover Medical School, Hannover, Deutschland

5 Department of Paediatric Surgery, Hannover Medical School Centre for Paediatrics and Adolescent Medicine, Hannover, Deutschland

6 Department of Paediatric Cardiology and Intensive Care Medicine, Hannover Medical School Centre for Paediatrics and Adolescent Medicine, Hannover, Deutschland

7 Department of Paediatric Pneumology, Dr. von Haunersches Kinderspital, German Center for Lung Research, University of Munich, Munich, Deutschland

8 Department of Paediatric Pneumology and Allergy, University Children's Hospital Regensburg (KUNO) at the Hospital St. Hedwig of the Order of St. John, University of Regensburg, Regensburg, Deutschland

9 Department of Neonatology and Paediatric Intensive Care, Vestische Childrenhospital Datteln, University of Witten/Herdecke, Datteln, Deutschland

10 Department of Paediatric Haematology and Oncology, Hannover Medical School Centre for Paediatrics and Adolescent Medicine, Hannover, Deutschland

11 BREATH (Biomedical Research in End-stage and obstructive Lung Disease Hannover), German Center for Lung Research (DZL), Hannover, Deutschland
Key words

air leak, persistent bronchopleural fistula, interventional bronchus occlusion, secondary spontaneous pneumothorax, pneumothorax, Amplatzer devices

\section{Schlüsselwörter}

Luftleckage, Persistierende bronchopleurale Fistel, interventionelle Bronchusokklusion, sekundärer Spontanpneumothorax, Pneumothorax, Amplatzer Okkluder

received 31.08 .2021

accepted 31.08.2021

accepted 15.11.2021

published online $\quad 03.01 .2022$

\section{Bibliography}

Klin Padiatr 2022; 234: 293-300

DOI 10.1055/a-1697-5624

ISSN $\quad 0300-8630$

(C) 2022. Thieme. All rights reserved.

Georg Thieme Verlag KG, Rüdigerstraße 14,

70469 Stuttgart, Germany

Correspondence

PD Dr. Nicolaus Schwerk

Hannover Medical School

Paediatric Pulmonology, Allergology and Neonatology

Carl-Neuberg-Straße 1

30625 Hannover

Deutschland

Tel.: +49/511/5323 251, Fax: +49/511/5329 125

schwerk.nicolaus@mh-hannover.de

* Contributed equally as co-first authors. 


\section{ABSTRACT}

Background: Persistent air leak (PAL) is a severe complication of secondary spontaneous pneumothorax (SSP). Surgical interventions are usually successful when medical treatment fails, but can be associated with significant complications and loss of potentially recoverable lung parenchyma. Methods: Retrospective analysis of efficacy and safety of interventional bronchus occlusions (IBO) using Amplatzer devices (ADs) in children with PAL secondary to SSP. Results: Six patients (four males, 4-15 years of age) underwent IBO using ADs as treatment for PAL. Necrotizing pneumonia (NP) was the most common cause $(n=4)$ of PAL. Three patients were previously healthy and three suffered from chronic lung disease. All patients required at least two chest tubes prior to the intervention for a duration of 15-43 days and all required oxygen or higher level of ventilatory support. In three cases, previous surgical interventions had been performed without success. All children improved after endobronchial intervention and we observed no associated complications. All chest tubes were removed within 5-25 days post IBO. In patients with PAL related to NP $(n=4)$, occluders were removed bronchoscopically without re-occurrence of pneumothorax after a mean of 70 days (IQR: 46.5-94). Conclusion: IBO using ADs is a safe and valuable treatment option in children with PAL independent of disease severity and underlying cause. A major advantage of this procedure is its less invasiveness compared to surgery and the parenchyma- preserving approach.

\section{ZUSAMMENFASSUNC}

Hintergrund: Die persistierende Luftleckage stellt eine schwere Komplikation eines sekundären Spontanpneumothorax (SSP) dar. Chirurgische Interventionen sind bei erfolgloser konservativer Therapie oft erfolgreich aber können mit schweren Komplikationen und dem Verlust von potentiell erholungsfähigem Lungengewebe behaftet sein. Ziel: Retrospektive Analyse über die Effektivität und Sicherheit von interventionellen BronchusOkklusionen (IBO) mit Amplatzer Devices (ADs) bei Kindern mit persistierender Luftleckage. Ergebnise: Bei 6 Patienten (4 männlich, Alter 4-15 Jahre) wurde eine IBO zur Therapie einer persistierenden Luftleckage durchgeführt. Die nekrotisierende Pneumonie (NP) war die häufigste zugrundeliegende Ursache einer persistierenden Leckage $(n=4)$. 3 Kinder waren zuvor gesund, bei 3 Kindern lag eine chronische Lungenerkrankung vor. Alle Patienten benötigten vor Intervention mindestens 2 Thoraxdrainagen für 15-43 Tage und alle Kinder benötigten Sauerstoff oder eine zusätzliche Atemunterstützung. Bei 3 Patienten erfolgten zuvor erfolglose chirurgische Interventionen. Es traten keine Komplikationen im Zusammenhang mit der IBO auf. Alle Patienten profitierten von der Prozedur, die Thoraxdrainagen konnten nach 5-25 Tagen gezogen werden. Bei allen Kindern mit persistierender Luftleckage aufgrund einer NP $(n=4)$ wurden die ADs nach durchschnittlich 70 Tagen (IQR:46.5-94) entfernt ohne dass ein Pneumothorax-Rezidiv auftrat. Schlussfolgerung: Die IBO mithilfe von ADs stellt unabhängig von der Ursache und Krankheitsschwere ein vielversprechendes und sicheres Therapieverfahren zur minimalinvasiven Behandlung von Kindern mit persistierender Luftleckage dar. Vorteile dieser Prozedur im Vergleich zu operativen Verfahren sind die geringe Invasivität und der parenchymerhaltende Ansatz.

\section{Introduction}

Persistent air leak (PAL), defined as an air leak that persists for greater than 5-7 days [1], is a rare but potentially life-threatening complication in children with alveolar-pleural fistulas (APF) or bronchopleural fistulas (BPF) following traumatic-, iatrogenic-, primary or secondary spontaneous pneumothorax (SSP). SSP is defined as accumulation of air in the pleural cavity in patients with pre-existing lung disease [2]. Although data on the overall incidence of PAL in children are not available, necrotizing pneumonia (NP) is likely the most common cause $[3,4]$. PAL has been reported in up to $33 \%$ of children hospitalized for NP in a recently published retrospective single center study [5]. In addition to the direct impact on respiration and gas exchange, PAL is associated with secondary complications like immobilization, pain, impaired mucus clearance and increased risk for pulmonary or pleural infections [6]. Furthermore, PAL prevents the maintenance of positive end-expiratory pressure during mechanical ventilation. Therefore, PALs are associated with high morbidity, extended duration of chest tube therapy and prolonged hospital stay, and higher resource utilization [7]. Unfortunately, no data on mortality rates in children exists, but mortality from PAL ranges from $16 \%-72 \%$ in adult patients $[8,9]$. Chest tube placement is the current standard of care $[10,11]$ but is not always sufficient to achieve adequate expansion of the affected lung and sustained contact of the visceral pleura to the parietal pleura, which is a precondition for the healing of the defect [12]. Furthermore, continuous suction through chest tubes, often applied in patients with PALs to evacuate the pleural space, may prevent spontaneous healing due to continuous flow of air through the lesion. Chemical or autologous blood pleurodesis represent a viable treatment option in patients with PAL [13-15] but can cause significant complications including tension pneumothorax secondary to obstruction of the chest tube and empyema [16]. Furthermore, pleurodesis can be ineffective, especially in the absence of continuous contact of the lung surface to the thoracic cavity. Therefore, current guidelines on the management of spontaneous pneumothorax recommend surgical treatment in case of PAL when medical treatment fails $[17,18]$. Surgical approaches include video-assisted thoracoscopic surgery (VATS) or open thoracotomy with either mechanical or chemical pleurodesis or pleurectomy, wedge resection, direct stump closure with intercostal muscle reinforcement, segmentectomy, lobectomy or even pneumectomy [19]. While surgical treatment is highly effective and safe in most cases, it can be associated with complications such as bleeding, pain, wound infections and loss of potentially recoverable lung tissue $[6,20]$. Many prom- 
ising case reports or case series on interventional bronchus occlusion in adult patients with PAL have been published using various devices, primarily one-way endobronchial valves (EBV) [6]. To date, reports on successful EBV-placement in children with PAL are limited to a total number of 6 patients [12, 21, 22]. Another viable treatment option for PAL is interventional bronchial occlusion using Amplatzer devices (ADs). ADs are self-expanding devices made from a Nitinol wire mesh, designed to provide transcatheter closure of blood vessels or congenital heart defects. ADs come in various configurations and sizes, and their deployment characteristics make them an attractive option. They can be fully deployed, retrieved, and repositioned prior to detachment which is a critical advantage for precise positioning and occlusion of the fistula. Although there are several case reports and case series on successful treatment of PAL with ADs in adult patients [20, 23-27], no pediatric cases have as yet been published. Here, we describe our first experiences regarding the feasibility, efficacy and safety of IBO using ADs in children with secondary spontaneous pneumothorax and PAL.

\section{Methods}

\section{Study Design}

We performed a retrospective analysis of feasibility, efficacy and safety of IBO using ADs in patients below 18 years of age with PAL after SSP between January 2016 and December 2020.

\section{Data collection}

Demographic data as well as information on clinical symptoms, disease courses, pre-existing diseases, radiological findings, number of chest tubes, chest tube duration, respiratory support, surgical interventions and medical treatment before and after intervention, length and number of interventions, number and types of devices used, intraprocedural vital signs and radiation dose were collected from patient's medical records.

\section{Patient selection}

Children with PAL were carefully evaluated by a multidisciplinary team consisting of pediatric pulmonologists, pediatric surgeons, pediatric intensivists, pediatric anesthesiologists and pediatric interventional cardiologists. Patients were considered candidates for IBO after exhaustion of all medical treatment options and if a surgical procedure was considered to pose a high risk of serious complications and/or a treatment failure. Parents provided informed consent following detailed counselling regarding the off-label use of $A D s$, possible complications, and alternative treatment options.

\section{Anesthetic management}

Standard monitoring consisting of electrocardiography, noninvasive BP measurement and pulse oximetry was established prior to anesthesia. Intravenous access was obtained if not already established. Anesthesia was started with intravenous injection of $5 \mathrm{mg} / \mathrm{kg}$ Propofol and maintained by a total intravenous anesthesia (TIVA) with $8-15 \mathrm{mg} / \mathrm{kg} / \mathrm{h}$ of Propofol and 0,3-0,5 $\mu \mathrm{g} / \mathrm{kg} / \mathrm{min}$ of Remifentanil. Volatile anesthetics were avoided in order to prevent environmental contamination of the staff. Depth of sedation was monitored by EEG.
Except for patient 1 who has already been intubated in the intensive care unit, airway management consisted of a single-use inflatable laryngeal mask as a supraglottic airway device. The larger intraluminal space provided by the laryngeal mask offers an advantage over conventional intubation, as this provides more space for a large bronchoscope and occluder equipment and allows better ventilation with lower airway pressure. End-tidal CO2 was consistently monitored. A conductive warming air blanket was used to preserve normothermia during the procedure. Continuous esophageal temperature measurement was employed. After intervention, most patients underwent rapid weaning and arrived in the post anesthesia care unit (PACU) awake and breathing spontaneously.

\section{Interventional bronchus occlusion (IBO)}

Procedures were performed by an experienced multidisciplinary team including pediatric pulmonologists, pediatric cardiologists and pediatric anesthesiologists in the pediatric cardiac catheterization laboratory, allowing the use of fluoroscopy when needed. Prior to intervention, chest tubes were connected to a digital thorax drainage system (Thopaz, MEDELA) which provides quantitative real time data on the air leak. As APFs or BPFs were localized peripherally in all patients and could therefore not be visualized directly by the bronchoscope, a balloon catheter (Arndt Airway Catheter, Cook Medical) was used to sequentially occlude the bronchial segments to locate the airway leading to the fistula [28, 29]. When bronchoscopes with a working channel of at least 2,0 mm diameter were used the balloon catheter was advanced directly through the working channel. In smaller children, we employed a hybrid technique (passing the guiding catheter outside the working channel into the bronchi under simultaneous bronchoscopic control). In cases with multiple fistulas, more than one balloon catheter was used and different bronchi were blocked simultaneously until the fistula flow stopped. On some occasions, fistula flow diminished or ceased completely after induction of anesthesia, making indirect identification of the fistula difficult or even impossible. In this case, bronchography was applied for direct visualization of the air leak. After the bronchi leading to the fistula were identified, a guidewire was passed under fluoroscopic and bronchoscopic control beneath the bronchoscope into the target bronchus. A guiding catheter or sheath for the delivery of of the AD was passed over the guidewire which was subsequently passed over the guidewire. The device was then advanced through the sheath or guiding catheter and deployed into the bronchus under bronchoscopic and fluoroscopic surveillance. Device size was calculated using previously obtained computer tomography images as well as direct measurement during bronchoscopy and bronchography using devices at least 1-2 mm larger than the bronchial diameter. Chest tubes were left in place for at least 24 hours after the procedure and removed when the 24-hour graph of the Thopaz-System indicated no fistula flow and the affected lung was completely expanded on chest$\mathrm{x}$-ray. In some patients with multiple fistulas and diminished but persistent air leaks, the procedure was stopped due to prolonged anesthesia duration. In some cases, residual air leaks then resolved spontaneously in the days following the intervention. If not, patients underwent a second procedure. $>$ Fig. 1 illustrates the step-by-step procedure of interventional bronchus occlusion using patient 3 as an example. In all patients with NP, occluders were removed bron- 


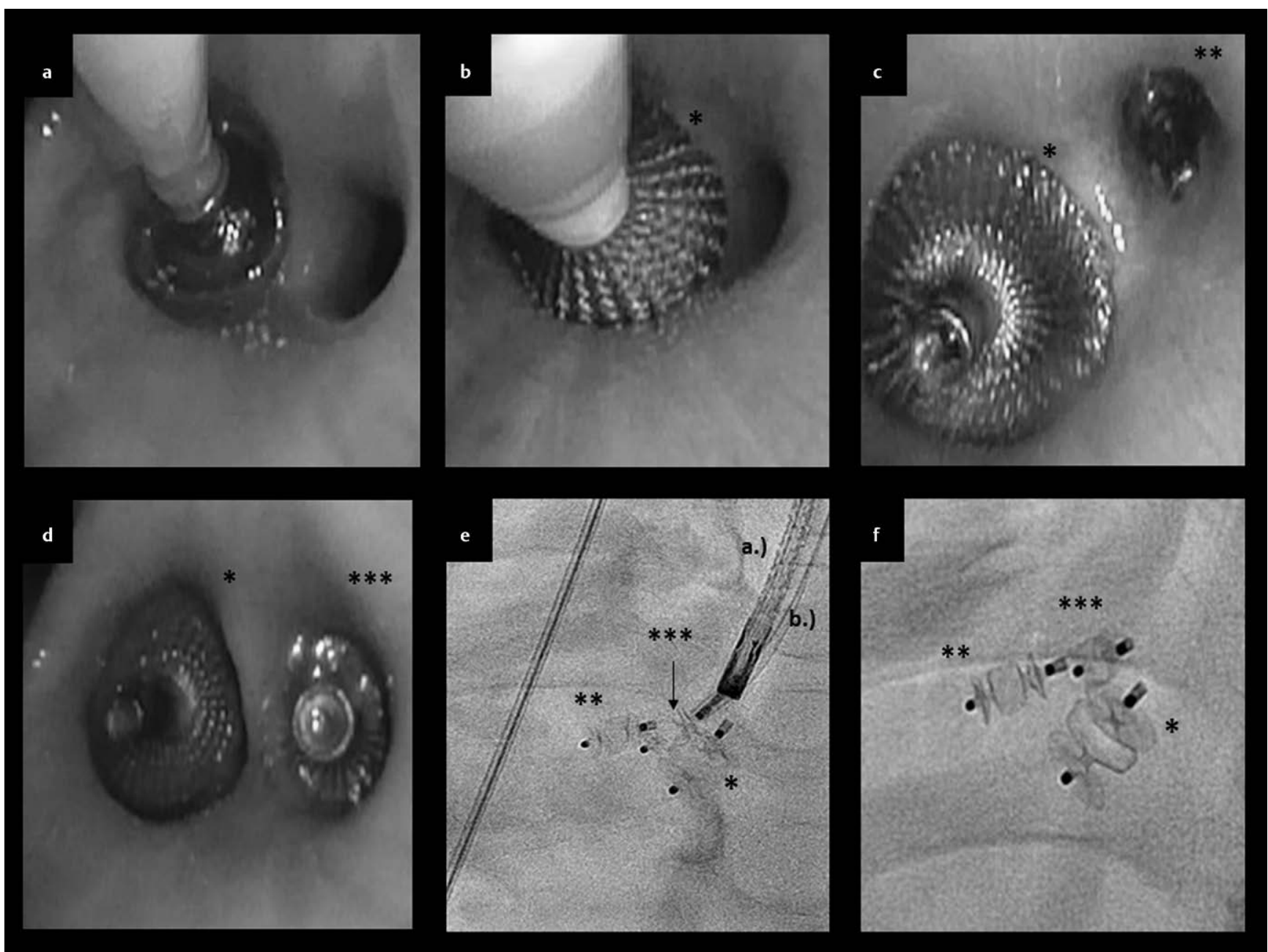

- Fig.1 Illustration of sequential IBO in patient 3 a: Block of the lower lobe bronchus using a $7 \mathrm{Fr}$. Arndt (Cook Medical) endobronchial blocker under simultaneous measurement of fistula flow using a Thopaz MEDELA. b: After significant decrease of the fistula flow, the first occluder $\left({ }^{*}\right)$ is placed under bronchoscopic guidance. c: A second occluder $\left({ }^{*}{ }^{*}\right)$ was placed into segment B6 after total cessation of fistula flow following occlusion of the segment by an Arndt blocker as described in A. $\mathbf{d}$ : Second intervention after recurrence of a small air leak. A third occluder $\left({ }^{* * *}\right)$ was placed into a subsegment of B6 which was not completely blocked by the second occluder. e: Fluoroscopic view directly after insertion of occluder 3 ( ${ }^{* * *}$ ). Bronchoscope (a.) and sheath (b.) are still in place. f: Magnification of implanted devices after removal of bronchoscope and sheath.

choscopically using flexible forceps when closure of the fistula was suspected based on clinical and radiological findings.

\section{Devices}

In all cases Amplatzer devices (ADs) were used. In all but one case, Amplatzer Vascular Plugs II (Abbott, Chicago, Illinois, USA) in different sizes were used. In one patient Amplatzer Duct Occluder II AS (Abbott, Chicago, Illinois, USA) were additionally applied. Bronchoscopies were performed with Olympus Europa (SE \& Co. KG, Hamburg, Germany) pediatric flexible fiberoptic bronchoscopes (3C160, Q180, XP160F).

\section{Statistical analysis}

All statistical analyses were performed using Microsoft Excel. Descriptive data were calculated as mean with interquartile range (IQR). Categorical data were reported as frequencies and percentages.

\section{Ethical approval}

Study approval by the institutional ethical review board was waived given its retrospective observational design. All representatives of pediatric patients had previously provided written informed consent regarding anonymized use of personal clinical data for research purposes.

\section{Results}

Between January 2016 and December 2020, seven children with PAL were referred to our institution. One previously healthy, 2-yearold boy with right sided PAL related to NP was already treated with two chest tubes for 14 days and need of oxygen underwent IBO of the right upper lobe bronchus using a $4 \mathrm{~mm}$ Amplatzer Vascular Plug II without any complications. Fistula flow decreased significantly after intervention, allowing prompt removal of one chest tube and cessation of supplemental oxygen therapy. As PAL per- 
sisted (with significantly decreased fistula flow) a second intervention was planned. One day before the second intervention and 10 days after the initial IBO, the patient died suddenly and unexpectedly. Post-mortem imaging showed the occluder in the correct position and an association with the NP or the intervention and the sudden death could be definitely excluded by subsequent autopsy. The cause of death remains unknown. For this reason, this patient was excluded from further analysis.

Mean age at first intervention of the remaining six patients (four males) was 9.8 years (IQR 5.5-14.6). PAL was secondary to NP in four cases. In the other two patients, PAL occurred as a SSP as a noninfectious complication of preexisting diffuse lung disease. Three children with NP were previously healthy and in one patient with cystic fibrosis (CF) NP occurred as a complication of the underlying disease. All patients were treated with chest tubes for a mean time of 28.2 days (IQR: 21.0-36.8). Before admission, three patients underwent surgery in the reffering hospitals (attempt of surgical coverage of a BPF in patient 1 ; surgical debridement and pleurectomy complicated by bronchial injury in patient 4; thoracoscopic bullectomy and apical pleurectomy in patient 5) without success. All patients required oxygen therapy, one patient required additional noninvasive ventilator support (patient 5), and one patient required venovenous extracorporeal membrane oxygenation (ECMO) support because ventilation alone was not sufficient due to an enormous fistula flow through the PAL (patient 1). Detailed Information on demographic data, causes of PALs and concomitant chronic diseases are given in $>$ Table $\mathbf{1}$.

Overall, 11 procedures with placement of 14 ADs were performed in 6 patients without any complications. Specifically, repositioning or removal of ADs was not required, and device migration, iatrogenic fistula formation, and infection was not observed. Three patients required a second intervention and, of these, two patients underwent a third procedure. All patients improved significantly after the first intervention with an observed drop or cessation of fistula flow and a reduced or absent need for supplemental oxygen. The mean time to removal of all chest tubes was 11.3 days (IQR:6.513.0) after first intervention and the patients were discharged between 6 and 28 days after first intervention in a good clinical con- dition and without supplemental oxygen (except patient 5 who was already oxygen dependent before PAL occurred). Patient 1 represents an especially challenging case as the child had been on a ventilator, ECMO and full sedated for 30 days prior to the first intervention. This patient required a total of four ADs, placed sequentially during three consecutive interventions. Therefore, this patient had a much longer chest tube duration and hospital stay compared to the others. Impressively, while areas of lung parenchyma initially seemed totally destroyed, the patient recovered completely and chest-x-ray was normal on 4 years post intervention ( $\mathbf{F i g . ~} \mathbf{2}$ ). In patient 5 , a persistent air leak despite previous placement of 3 occluders in the right upper lobe bronchus was successfully sealed by autologous blood and fibrin glue during the third procedure. Information on number of procedures and devices per patient, radiation time, chest tube duration, time until discharge after first intervention and time until removal of occluders (when performed) are given in $>$ Table 2 . ADs were removed in all patients with PAL related to NP $(n=4)$ after a mean of 70.0 days (IQR:46.5-94) post first intervention without any complications and without PAL reoccurrence. At a mean follow up time of 3.3 years (IQR: 3-3.3), three children were completely asymptomatic without any respiratory complaints and the one patient with CF was in a stable condition with respect to the underlying disease. In patient 5, occluders were left in place until successful bilateral sequential lung transplantation at our institution 7 month after IBO. In patient 6, both ADs are in place at last follow up. It is noteworthy that in this patient with CF and chronic colonization with mycobacterium abscessus, who is thus at increased risk for pulmonary infection, no infection related to bronchus occlusion has occurred despite the long duration of occluders remaining in-situ (5.6 years post intervention). Furthermore, because of the absence of PAL recurrence after intervention, previous plans to pursue lung transplantation for this patient were postponed. After the initiation of triple therapy with Tezacaftor, Elexacaftor and Ivacaftor, lung function has improved significantly and the patient reported high quality of life with minimal limitations during everyday activities on last follow up.

- Table 1 Demographic data and patients characteristics prior to interventional bronchial occlusion

\begin{tabular}{|c|c|c|c|c|c|c|}
\hline Patient no. & 1 & 2 & 3 & 4 & 5 & 6 \\
\hline Sex & $f$ & $f$ & $\mathrm{~m}$ & $\mathrm{~m}$ & $\mathrm{~m}$ & $\mathrm{~m}$ \\
\hline Age (yrs.) & 5.4 & 15.2 & 5.6 & 4.4 & 12.9 & 15.5 \\
\hline Cause of PAL & NP & NP & NP & NP & SSP & SSP \\
\hline Preexisting chronic lung disease & 1 & CF & 1 & 1 & $\begin{array}{l}\text { Pulmonary GVHD } \\
\text { after HSCT }\end{array}$ & CF \\
\hline Affected side & right & left & right & right & right & right \\
\hline $\begin{array}{l}\text { Number of chest tubes insertion before first } \\
\text { intervention }\end{array}$ & 5 & 4 & 5 & 5 & 3 & 2 \\
\hline $\begin{array}{l}\text { Number of days with at least one chest-tube } \\
\text { before first intervention }\end{array}$ & 30 & 43 & 21 & 39 & 21 & 15 \\
\hline Respiratory support at time of intervention & VV-ECMO & oxygen only & oxygen only & oxygen only & High-Flow & oxygen only \\
\hline Surgical treatment attempts before intervention & yes & no & no & yes & yes & no \\
\hline
\end{tabular}




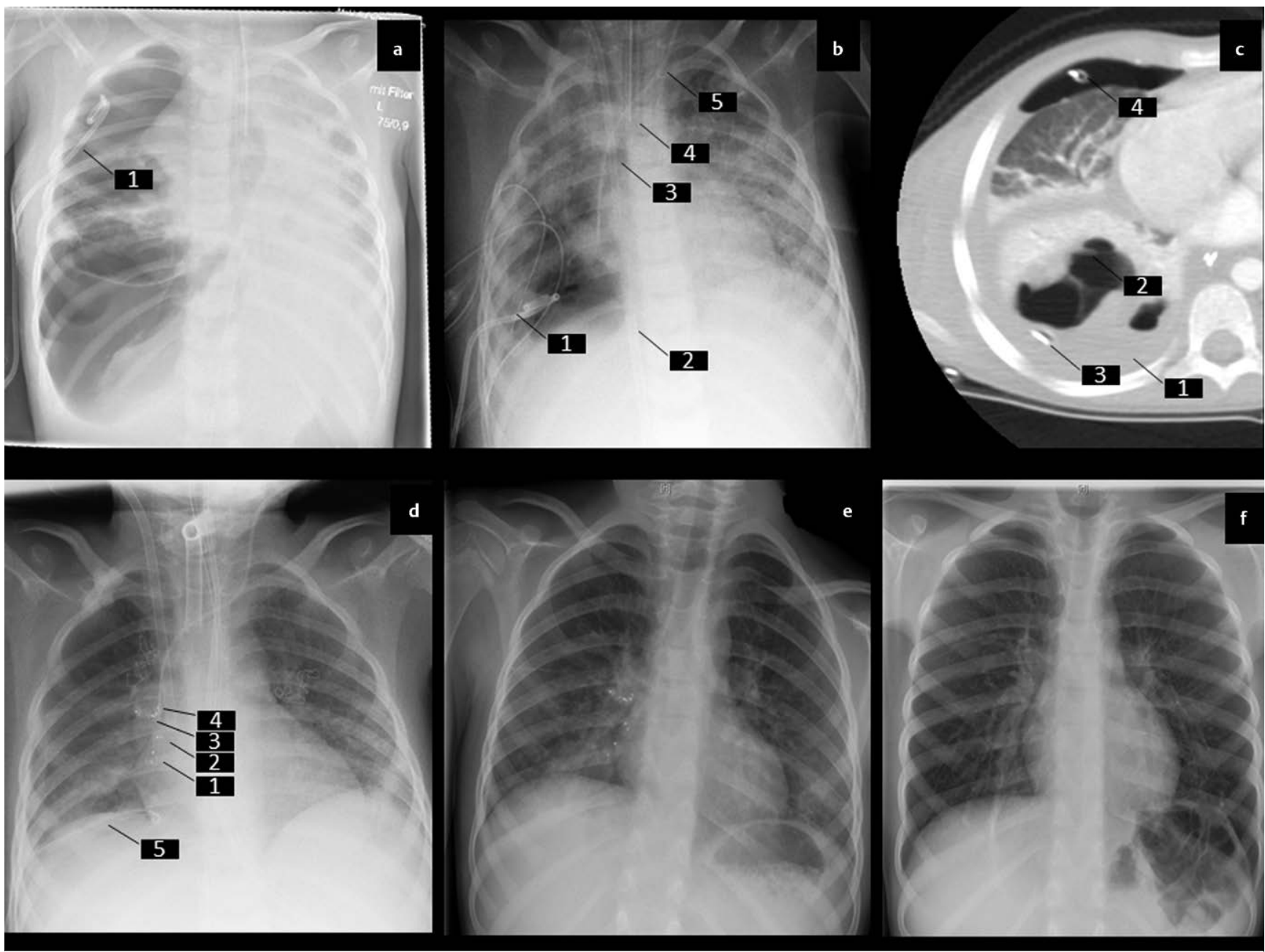

- Fig.2 Sequential Chest imaging before and after IBO and after removal of occluders in patient $1 \mathrm{a}$ : Chest $\mathrm{x}$-ray showing a right sided tension pneumothorax although a chest tube was inserted (1). b: Chest x-ray showing a persistent pneumothorax despite placement of another chest tube (1). Additionally there are bilateral diffuse ground glace opacities, consistent with ARDS. 2: ECMO-cannula coming from the right femoral vein; 3 : ECMO-cannula coming from the right jugular vein; 4 : tracheal tube; 5 : central venous line. c: Chest CT scan from the right lung showing a large seropneumothorax (1), a consolidated lower lobe with pneumathoceles (2) and a persistent pneumothorax despite 2 chest tubes $(3+4) \mathbf{d}$ : Chest $x$-ray after placement of multiple ADs (1-4) showing full expansion of the lung. The patient is still on ECMO, ventilated via a tracheal cannula and there is still one chest tube left (5). e: Last chest-x-ray before discharge. The ADs are still in place, the last chest tube was removed and the patient was decannulated. $\mathbf{f}$ : Last chest-x-ray on follow up 4 years post intervention. ADs were removed. Both lungs appear unaffected without consolidations, infiltrates or any other residual defects.

\section{Discussion}

We describe a novel interventional treatment approach for children with PAL complicating SSP. We demonstrated that IBO using ADs is safe even in critical ill patients.

A major advantage of the described procedure is its minimalinvasive character of this parenchyma preserving approach. In all six cases reported here, surgery could be avoided in favor of the IBO procedure. Even in children with chronic pulmonary lung disease and increased risk of pulmonary infections, we observed no infectious complications on follow up. Furthermore, no other adverse events such as bronchial injuries, irritations or occluder migration occurred. In most cases, ADs were eventually removed, leading to full functional recovery of the previously affected lung. Especially in children with SSP related to NP it was surprising to observe the enormous healing capacity of damaged lung tissue. Lung parenchymathat seemed destroyed on initial chest imaging in these patients, displayed near total recovery on long term follow up ( Fig. 2). This observation underlines the efficacy of this intervention and stresses its viability as an alternative treatment option to surgery. We show that IBO using ADs can be performed independent of patients' size or age as instruments do not have to pass through the working channel of the bronchoscope. Furthermore, in contrast to surgery, children do not experience pain after intervention and chest tubes can be removed after a relatively short time leading to early patient mobilization, avoidance of prolonged pain therapy and sedation and thus to a faster recovery with a corresponding shortening of hospital stay. Some of the children described here suffered from severe underlying progressive diffuse lung disease and had already undergone unsuccessful surgical procedures for their PALs. As result of these endobronchial interven- 
- Table 2 Characteristics of interventional bronchial occlusion and clinical course post intervention

\begin{tabular}{|c|c|c|c|c|c|c|}
\hline Patient & 1 & 2 & 3 & 4 & 5 & 6 \\
\hline Affected side & right & left & right & right & right & right \\
\hline Number and Localization of ADs 1st intervention & $2-\mathrm{B} 6$ & $1-\mathrm{B} 10$ & $2-\mathrm{LLB}+\mathrm{B} 6$ & $1-\mathrm{MLB}$ & $2-B 1+B 2$ & $2-B 2$ \\
\hline Number and Localization of ADs 2nd intervention & $1-B 9$ & 1 & $1-\mathrm{B} 6$ & 1 & $1-B 3$ & 1 \\
\hline Number and Localization of ADs 2nd intervention & $1-B 10$ & 1 & 1 & 1 & $1^{*}$ & 1 \\
\hline Total radiation time as dose area product cGycm2 & 701 & 2113 & 2348 & 1145 & n.a. & 215 \\
\hline Days until removement of the last chest tube after first intervention & 25 & 8 & 14 & 5 & 10 & 6 \\
\hline Days of hospitalization until discharge after first intervention & 28 & 10 & 9 & 7 & 21 & 6 \\
\hline Days until occluder extraction after first intervention & 97 & 93 & 48 & 42 & 1 & 1 \\
\hline
\end{tabular}

tions, lung transplantation could be postponed or rendered unnecessary in these patients. Nevertheless, multiple interventions were necessary in a relevant proportion of our patients.

It is relevant to note that ADs are not licensed for endobronchial occlusion. The only approved bronchial occluder for children is the endobronchial Watanabe-Spigot. Watanabe-Spigots are conical, non-self-expanding silicone occluders, available in different sizes and developed to treat pulmonary hemorrhage and PAL. In the original trial, which included no pediatric patients, only 23 of 60 adult patients experienced complete cessation of air leak after placement of the spigot [29]. Furthermore, Watanabe-Spigots are very challenging to handle, especially in children, rendering the risk of dislocation very high. In addition, due to the lack of self-expansion, they often fail to adequately seal the bronchi, often resulting in treatment failure. We previously had disappointing experiences with the use of spigots in children with severe pulmonary hemorrhage. Case reports in adults have noted successful closure of fistulas with various adhesives [6]. In our experience, however, gluing a bronchus alone is not sufficient. Moreover, adhesives cannot be accurately dosed and applied through the working channel of the bronchoscope, which increases the risk of accidental occlusion of unaffected bronchi. Nevertheless, additional autologous blood or fibrin glue might still be a treatment option when complete sealing by ADs fails, as shown in patient 5 .

An attractive and promising alternative to ADs are endobronchial valves (EBV). EBV are one-way valves that are deployed in the lobar, segmental, or subsegmental airways with a flexible bronchoscope. They are engineered to block air from flowing through the fistula while allowing distal secretions to drain normally. The two largest published studies supporting the use of EBV for PAL are retrospective analyses in adults reporting success rates of over $90 \%$ $[30,31]$. One case series including four children and two single case reports have demonstrated that IBO using EBVs is also applicable even in critically ill children $[12,21,22]$. An obstacle to the use of EBVs in younger children is the large diameter of the application system, which has to be passed through the working channel of the bronchoscope and requires a minimum diameter of $2,1 \mathrm{~mm}$. Therefore, EBVs can only be used in older children and adolescents.

Our study is limited by its retrospective design, the small number of patients and the absence of a control group. However, facing the individual character and severness of SSPs in different age groups, propective studies will potentially not be achievable. Thus cases should be systematically documented and collected, for example within the framework of registries, to ensure high quality retrospective analyses are possible in future.

\section{Conclusion}

We describe a technique of IBO using ADs in children as a non-invasive, safe and valuable treatment option for PAL. Advantages include reduced pain, high efficacy, a low rate of complications and the ability to preserve lung parenchyma. Given their expertise in positioning and deploying these devices, collaboration between pediatric pulmonologists and interventional cardiologists is recommended.

\section{Contributor's Statement}

N.Schwerk, C.Happel, H.Bertram, developed the procedure. N.Schwerk, K.Schütz, C.Happel, H.Bertram designed the research. K. Schütz, N. Schwerk, O. Keil, A. Zychlinsky Scharff and C. Happel designed and primarily wrote the manuscript and compiled tables and figures. All authors made substantial contributions to the conception, drafting and revising of the manuscript, and final approval of the submitted version.

\section{Acknowledgements}

The authors would like to thank the patients and families for their contribution. They thank all persons involved in care of the patients and implementation of the interventions.

\section{Conflict of Interest}

The authors declare that they have no conflict of interest.

\section{References}

[1] Dugan KC, Laxmanan B, Murgu S, Hogarth DK. Management of Persistent Air Leaks. Chest 2017; 152: 417-423 
[2] Robinson PD, Cooper P, Ranganathan SC. Evidence-based management of paediatric primary spontaneous pneumothorax. Paediatr Respir Rev 2009; 10: 110-117. quiz 117

[3] Sawicki GS, Lu FL, Valim C, Cleveland RH, Colin AA. Necrotising pneumonia is an increasingly detected complication of pneumonia in children. Eur Respir ] 2008; 31: 1285-1291

[4] Kagan S, Nahum E, Kaplan E, Kadmon G, Gendler Y, Weissbach A. Persistent pulmonary air leak in the pediatric intensive care unit: Characteristics and outcomes. Pediatr Pulmonol 2021; 56: 2729-2735

[5] McKee AJ, Ives A, Balfour-Lynn IM. Increased incidence of bronchopulmonary fistulas complicating pediatric pneumonia. Pediatr Pulmonol 2011; 46: 717-721

[6] Sakata KK, Reisenauer JS, Kern RM, Mullon JJ. Persistent air leak review. Respir Med 2018; 137: 213-218

[7] Liberman M, Muzikansky A, Wright CD, Wain JC, Donahue DM, Allan JS et al. Incidence and risk factors of persistent air leak after major pulmonary resection and use of chemical pleurodesis. Ann Thorac Surg 2010; 89: 891-897. discussion 897-8

[8] Sirbu H, Busch T, Aleksic I, Schreiner W, Oster O, Dalichau H. Bronchopleural fistula in the surgery of non-small cell lung cancer: incidence, risk factors, and management. Ann Thorac Cardiovasc Surg 2001; 7 : 330-336

[9] Sonobe M, Nakagawa M, Ichinose M, Ikegami N, Nagasawa M, Shindo T. Analysis of risk factors in bronchopleural fistula after pulmonary resection for primary lung cancer. Eur J Cardiothorac Surg 2000; 18 : 519-523

[10] MacDuff A, Arnold A, Harvey J, Pleural BTS. DiseGuideline Group. Management of spontaneous pneumothorax: British Thoracic Society Pleural Disease Guideline 2010. Thorax 2010; 65: ii 18-31

[11] Robinson PD, Cooper P, Ranganathan SC. Evidence-based management of paediatric primary spontaneous pneumothorax. Paediatr Respir Rev 2009; 10: 110-117. quiz 117

[12] Jaspers GJ, Willemse BWM, Kneyber MC]. Endobronchial valve placement for a severe pneumothorax in a child on ECLS. Pediatr Pulmonol 2019; 54: 1875-1877

[13] Chambers A, Routledge T, Bille A, Scarci M. Is blood pleurodesis effective for determining the cessation of persistent air leak? Interact Cardiovasc Thorac Surg 2010; 11: 468-472

[14] Heffner JE, Standerfer RJ, Torstveit J, Unruh L. Clinical efficacy of doxycycline for pleurodesis. Chest 1994; 105: 1743-1747

[15] Lang-Lazdunski L, Coonar AS. A prospective study of autologous 'blood patch' pleurodesis for persistent air leak after pulmonary resection. Eur J Cardiothorac Surg 2004; 26: 897-900

[16] Manley K, Coonar A, Wells F, Scarci M. Blood patch for persistent air leak: a review of the current literature. Curr Opin Pulm Med 2012; 18 : 333-338

[17] Baumann MH, Strange C, Heffner JE, Light R, Kirby T], Klein J et al. Management of spontaneous pneumothorax: an American College of Chest Physicians Delphi consensus statement. Chest 2001; 119: 590-602
[18] MacDuff A, Arnold A, Harvey J, Pleural BTS. DiseGuideline Group. Management of spontaneous pneumothorax: British Thoracic Society Pleural Disease Guideline 2010. Thorax 2010; 65: ii 18-31

[19] Schweigert M, Dubecz A, Beron M, Ofner D, Stein HJ. Surgical therapy for necrotizing pneumonia and lung gangrene. Thorac Cardiovasc Surg 2013; 61: 636-641

[20] Akulian J, Pathak V, Lessne M, Hong K, Feller-Kopman D, Lee H et al. A novel approach to endobronchial closure of a bronchial pleural fistula. Ann Thorac Surg 2014; 98: 697-699

[21] Toth JW, Podany AB, Reed MF, Rocourt DV, Gilbert CR, Santos MC et al. Endobronchial occlusion with one-way endobronchial valves: a novel technique for persistent air leaks in children. J Pediatr Surg 2015; 50 : 82-85

[22] Criss CN, Barbaro R, Bauman KA, Folafoluwa O, Vellody R, Jarboe MD. Selective Management of Multiple Bronchopleural Fistulae in a Pediatric Patient on Extracorporeal Membrane Oxygenation: A Multidisciplinary Approach. J Laparoendosc Adv Surg Tech A 2018; 28 : 1271-1274

[23] Klotz LV, Gesierich W, Schott-Hildebrand S, Hatz RA, Lindner M. Endobronchial closure of bronchopleural fistula using Amplatzer device. J Thorac Dis 2015; 7: 1478-1482

[24] Gomez Lopez A, Garcia Lujan R. AD -artment of Respiratory Medicine, University Hospital 12 de Octubre, Madrid,,Spain., De Pablo Gafas A, Hernandez Hernandez F, Villena Garrido V, Valipour A, et al. First use of Amplatzer device for bronchopleural fistula after lung transplantation. Thorax 2017; 72: 668-670

[25] Fruchter O, Kramer MR, Dagan T, Raviv Y, Abdel-Rahman N, Saute M et al. Endobronchial closure of bronchopleural fistulae using amplatzer devices: our experience and literature review. Chest 2011; 139 : 682-687

[26] Fruchter O, El Raouf BA, Abdel-Rahman N, Saute M, Bruckheimer E, Kramer MR. Efficacy of bronchoscopic closure of a bronchopleural fistula with amplatzer devices: long-term follow-up. Respiration 2014; 87: $227-233$

[27] Papiashvilli M, Bar I, Sasson L, Priel IE. Endobronchial closure of recurrent bronchopleural and tracheopleural fistulae by two amplatzer devices. Heart Lung Circ 2013; 22: 959-961

[28] Lois M, Noppen M. Bronchopleural fistulas: an overview of the problem with special focus on endoscopic management. Chest 2005; 128 : 3955-3965

[29] Lazarus DR, Casal RF. Persistent air leaks: a review with an emphasis on bronchoscopic management. J Thorac Dis 2017; 9: 4660-4670

[30] Gilbert CR, Casal RF, Lee H], Feller-Kopman D, Frimpong B, Dincer HE et al. Use of One-Way Intrabronchial Valves in Air Leak Management After Tube Thoracostomy Drainage. Ann Thorac Surg 2016; 101: 1891-1896

[31] Travaline JM, McKenna RJ Jr, De Giacomo T, Venuta F, Hazelrigg SR, Boomer $\mathrm{M}$ et al. Treatment of persistent pulmonary air leaks using endobronchial valves. Chest 2009; 136: 355-360 